\title{
Prevalence and associated factors of visual impairment among adults at Debre Berhan town, North Shewa, Ethiopia
}

\author{
Natnael Lakachew Assefa ${ }^{1^{*}}$ D, Addisu Wondifraw Admas ${ }^{2}$ and Nebiyat Feleke Adimasu
}

\begin{abstract}
Background: Visual impairment refers to presenting distance visual acuity worse than $6 / 18$ in the worst eye. It remains a global challenge that greatly affects the mobility, social participation and the quality of life of the people. This study was aimed to determine the prevalence and associated factors of visual impairment among adults aged $\geq 18$ years.

Methods: A community-based cross-sectional study was conducted at Debre Berhan town. Systematic random sampling method was employed to select the study participants from adult's aged $\geq 18$ years. Data was collected by interview with a pre-tested semi structured questionnaire. Both anterior and posterior segment ocular examinations were done by Optometrists and Ophthalmologist. After all ocular examinations adult's aged $\geq 18$ years with presenting Visual acuity of $<6 / 18$ in the worst eye were considered as visually impaired. Multivariate logistic regression was used to identify the determinant factors and $p$ value less than 0.05 was considered as statistically significant.
\end{abstract}

Results: A total of 416 participants were enrolled in the study with a $98.6 \%$ response rate. The prevalence of visual impairment among adults aged $\geq 18$ years was $16.8 \%$ (95\% Cl, 13.5-20.2\%). Among the overall prevalence of visually impaired adults 27 (6.49\%) had bilateral VI and 43 (10.34\%) had monocular VI. Aged $>64$ years (AOR = 12.18, 95\%Cl: 4.47-33.20), illiterates $A O R=3.02,95 \% \mathrm{Cl}: 1.36-6.72)$, previous eye trauma ( $\mathrm{AOR}=4.44,95 \% \mathrm{Cl}: 1.64-12.04$ ), family size > 5 (AOR: $4.44,95 \% \mathrm{Cl}: 1.43-13.75$ ) and family history of eye problem (AOR $=7.02,95 \% \mathrm{Cl}: 1.95-25.22$ ) had statistically significant association with visual impairment.

Conclusions: Prevalence of visual impairment among adults was found to be a significant public health problem. Older age, illiterates, previous eye trauma, large family size and family history eye problem were positively associated with visual impairment.

Keywords: Visual impairment, Associated factors, Adults, Debre Berhan, Ethiopia

\footnotetext{
* Correspondence: natiuog@gmail.com

'Department of Optometry, School of Medicine, College of Medicine and Health Science, University of Gondar, Gondar, Ethiopia

Full list of author information is available at the end of the article
}

(C) The Author(s). 2020 Open Access This article is licensed under a Creative Commons Attribution 4.0 International License, which permits use, sharing, adaptation, distribution and reproduction in any medium or format, as long as you give appropriate credit to the original author(s) and the source, provide a link to the Creative Commons licence, and indicate if changes were made. The images or other third party material in this article are included in the article's Creative Commons licence, unless indicated otherwise in a credit line to the material. If material is not included in the article's Creative Commons licence and your intended use is not permitted by statutory regulation or exceeds the permitted use, you will need to obtain permission directly from the copyright holder. To view a copy of this licence, visit http://creativecommons.org/licenses/by/4.0/ The Creative Commons Public Domain Dedication waiver (http://creativecommons.org/publicdomain/zero/1.0/) applies to the data made available in this article, unless otherwise stated in a credit line to the data. 


\section{Background}

Visual impairment (VI) refers to a functional limitation of the eye or visual system due to a disorder or disease that results in poor vision in the worst eye. According to World Health Organization (WHO) revised definition, it is defined as presenting distance visual acuity worse than $6 / 18$ in the worst eye [1]. Classification of severity of VI recommended by the Resolution of the International Council of Ophthalmology and WHO Consultation includes Moderate VI, Severe VI and blindness based on presenting VA worse than $6 / 18,6 / 60$, and $3 / 60$ respectively $[1,2]$. Among the global population 216.6 million were moderate or severe VI. The leading causes were uncorrected refractive error (116.3 million), cataract (52.6 million), age-related macular degeneration (8.4 million), glaucoma ( 4.0 million), and diabetic retinopathy (2.6 million) [3]. The prevalence of VI among adults aged 40 years and above in the South Indian State of Andhra Pradesh was 14.3\% [4], In Saudi among adults aged $\geq 18$ years was (23.5\%) [5], in East Delhi district among adults aged $\geq 40$ years and above was $11.4 \%$ [6] and in rural area of Coastal Karnataka state among adults aged $\geq 18$ years was $25.7 \%$ [7]. Based on the presenting visual acuity (PVA) prevalence of VI was different in African countries. In Ghana among Cocoa Farmers aged $\geq 40$ years was 22.7\% [8], In Upper Egypt among adults aged $\geq$ 40 years was 38.8\% [9] and In Southern Sudan among aged $\geq 5$ years was $11.8 \%$ [10]. Based on 2006 national survey blindness and low vision were major public health problems in Ethiopia. Based on presenting vision in the better eye the national prevalence of blindness and low vision was 1.6 and $3.7 \%$ respectively. The major causes of low vision were cataract $(42.3 \%)$, refractive error (33.4\%), trachomatous corneal opacity (7.7\%), other corneal opacity (5.9\%) and macular degeneration (4.6\%) [11].

VI remains to be a major public health problem especially in low and middle income countries which was estimated to be four times higher than in high-income countries [12]. VI affects the quality of life and socioeconomic characteristics of the people like mobility, social participation and find a job [13]. Hence, their ability to find employment and support themselves and provide for their families is diminished [14]. However, there was no previous study on the prevalence and associated factors of VI among adults at a community level in Ethiopia as well as in the study area. There is limited access to eye care service for the large number of populations at Debre Berhan town in which only one eye care service center and few eye care professionals are providing services for more than about 80,000 populations. So the current study aimed to estimate the total magnitude of VI at the town and it might be helpful for health authorities to plan strategies for eye care services in the study area.

\section{Methods}

Study design, setting and sampling

A community-based cross-sectional study was conducted at Debre Berhan town from April 30, 2018 to May 15, 2018. Debre Berhan town is located in North Shewa, Amhara Regional State, $120 \mathrm{~km}$ away from Addis Ababa (the capital city of Ethiopia) in the north direction and $688 \mathrm{~km}$ from Bahir Dar (capital city of Amhara National Regional State). It has 88,375 total populations (39,961 males and 48 , 414 females), of which $64.4 \%$ are adults aged $\geq 18$ years (unpublished data obtained from Debre Berhan town woreda health office). All adults aged $\geq 18$ years who lived at Debre Berhan town for at least 6 months were the source and study population.

Sample size was determined with single population proportion formula. $n=\frac{\left(Z_{\alpha / 2}\right)^{2} P(1-P)}{d^{2}} \quad(n=$ Sample size, $\mathrm{Z}=$ The Value of $\mathrm{z}$ statistic at $95 \%$ confidence level $=1.96, \mathrm{P}-$ Proportion of visual impairment $=50 \%=0.5$ (Since community based study on the presenting visual acuity was not conducted in the study area or other similar areas which had related population characteristics and methodology of the current study, 50\% proportion was used), d Maximum tolerable error (marginal error) $5 \%=0.05, n=$ 384 ). By adding $10 \%$ nonresponse rate, the final sample size was estimated at 422 . In the study area, there were 20 , 770 households and nine kebeles (administrative groups). All administrative kebeles were included in the study by proportionally allocating the households in each kebele according to their size. Systematic random sampling method was employed to select the households by using an interval of constant $(\mathrm{k}=49, \mathrm{~K}$ was calculated as the total households [20,770] divided by sample size [422]). If more than one eligible adult's aged $\geq 18$ years were found in the selected household, a lottery method was used to recruit the sample.

\section{Operational definitions \\ Visual impairment}

VI was defined as presenting distance visual acuity worse than 6/18 to no light perception (NLP) in the worst eye. It was further classified into moderate VI (Presenting visual acuity (PVA) $<6 / 18-\leq 6 / 60)$, severe VI (PVA $<6 /$ $60-\leq 3 / 60$ ), blindness (PVA $<3 / 60-\mathrm{NLP}$ ), monocular moderate VI (PVA of $<6 / 18-\leq 6 / 60$ in one eye and $6 / 6$ $-\leq 6 / 18$ in the other eye), monocular severe VI (PVA < $6 / 60-\leq 3 / 60$ in one eye and $6 / 6-6 / 60$ in the other eye) and monocular blindness (PVA $<3 / 60$ to NLP in one eye and PVA of 6/6-3/60 in the other eye) [1].

\section{Smoking}

Smokers were those who smoked one stick of cigarette at least once per day and nonsmokers those who never smoke cigarette [15]. 


\section{Eye trauma}

Self-reported previous history of any trauma to the eye.

\section{Family history of eye problem}

Were those participants who had positive history of vision problems in their family members/near relatives (parents \& grandparents).

\section{Data collections and examination procedures}

The questionnaire was pre-tested for $5 \%$ of the sample at Chacha town which is $10 \mathrm{~km}$ away from Debre Berhan and re-adjusted accordingly. The questionnaire was contained socio-demographic, socio-economic, behavioral factors and ocular examinations which was used to collect the data. Ocular examinations were done by using Snellen's "E" optotype chart, pinhole disc, pen torch, direct ophthalmoscope and $2.5 \times$ magnifying loupe. Optometrists and Ophthalmologist were involved in the data collection process. After took the informed written consent from the study participant, Optometrists had measured the presenting distance VA at $6 \mathrm{~m}$ for each eye separately. Adults with VA of less than 6/18 in the worst eye were rechecked with pinhole. Presenting Visual acuity of $<6 / 18$ in the worst eye were considered as VI. An improvement of VA with pinhole and clear ocular media with direct ophthalmoscopy was confirmed as VI due to refractive error. Both anterior and posterior segment eye examination were done for all cases to determine the possible abnormalities that decrease the VA and all the findings were documented. Those visual impaired participants who had undetermined eye problems were consulted to the Ophthalmologist for detailed eye examination and the required data were collected after the diagnosis was confirmed. All study participants who had VI were linked to the referral hospital for appropriate management and follow up.

\section{Statistical analysis}

All the collected data was entered, coded and cleaned to EPI INFO 7 and then exported in to SPSS (Statistical Package for Social Science) version 20 and analyzed. Descriptive results were presented by using frequency, percentages, charts, tables, graphs and summary statistics. Binary logistic regression model was used to find out the association between VI and independent variables. Multivariable binary logistic regression model was used to determine the factors adjusted for potential confounders. Adjusted Odds Ratio (AOR) and 95\% confidence interval (CI) were used to show the strength of association. Model fitness was checked by Hosmer and Lemeshow goodness of fit test. Multi co-linearity was checked by variable inflation factor (VIF) and tolerance. Finally, those factors with $p$-value of less than 0.05 were considered as statistically significant.

\section{Results}

Socio-demographic characteristics of study participants A total of 416 participants were included in the study with a $98.6 \%$ response rate. The median age of participants was 36 years with interquartile range (IQR: 27-52 years). Among the study participants 247 (59.4\%) were females (See Table 1).

\section{Socio-economic characteristics of study participants}

The median family monthly income was 101.07 US\$ with inter quartile range of [IQR: 57.27-151.67]. Most of the study participants 354 (85.1\%) had no health insurance (See Table 2).

\section{Systemic co-morbidities and behavioral characteristics of study participants}

Among the study participants 405 (97.8\%) were nonsmokers. History of systemic hypertension and diabetic mellitus were found in $21(5.0 \%)$ and $9(2.2 \%)$ participants respectively. Two hundred eighty three $68.0 \%$ of participants had no history of eye checkup (See Table 3).

Table 1 Socio-demographic characteristics of adults aged $\geq 18$ years at Debre Berhan town, North Shewa, Ethiopia, 2018 ( $n=$ $416, n=$ number of study participants)

\begin{tabular}{|c|c|c|}
\hline Variable & Frequency & Percentage (\%) \\
\hline \multicolumn{3}{|l|}{ Age (years) } \\
\hline $18-39$ & 235 & 56.5 \\
\hline $40-64$ & 123 & 29.6 \\
\hline$>64$ & 58 & 13.9 \\
\hline \multicolumn{3}{|l|}{ Gender } \\
\hline Male & 169 & 40.6 \\
\hline Female & 247 & 59.4 \\
\hline \multicolumn{3}{|l|}{ Religion } \\
\hline Orthodox & 345 & 82.9 \\
\hline Muslim & 27 & 6.5 \\
\hline Protestant & 32 & 7.7 \\
\hline Catholic & 12 & 2.9 \\
\hline \multicolumn{3}{|l|}{ Ethnicity } \\
\hline Amhara & 359 & 86.3 \\
\hline Oromo & 27 & 6.5 \\
\hline Tigrie & 13 & 3.1 \\
\hline Guragie & 17 & 4.1 \\
\hline \multicolumn{3}{|l|}{ Marital status } \\
\hline Single & 178 & 42.8 \\
\hline Married & 238 & 57.2 \\
\hline \multicolumn{3}{|c|}{ Family history of eye problem } \\
\hline Yes & 16 & 3.8 \\
\hline No & 400 & 96.2 \\
\hline
\end{tabular}


Table 2 Socio-economic characteristics of adults aged $\geq 18$ years at Debre Berhan town, North Shewa, Ethiopia, 2018 ( $n=416$, $n=$ number of study participants)

\begin{tabular}{|c|c|c|c|}
\hline Variables & Categories & Frequency & Percentage (\%) \\
\hline \multirow[t]{2}{*}{ Health insurance } & Yes & 62 & 14.9 \\
\hline & No & 354 & 85.1 \\
\hline \multirow[t]{2}{*}{ Occupations } & Employed & 155 & 37.3 \\
\hline & Not employed & 261 & 62.7 \\
\hline \multirow[t]{2}{*}{ Educational status } & Illiterate & 55 & 13.2 \\
\hline & Literate & 361 & 86.8 \\
\hline \multirow[t]{4}{*}{ Family monthly income (US\$) } & $<57.31$ & 106 & 25.5 \\
\hline & $57.31-101.07$ & 127 & 30.5 \\
\hline & $101.11-151.61$ & 84 & 20.2 \\
\hline & $>151.61$ & 99 & 23.8 \\
\hline
\end{tabular}

\section{Prevalence of visual impairment among adults}

The prevalence of VI among adults aged $\geq 18$ years was $16.8 \%$ [95\% CI: $13.5,20.2 \%$ ]. Nearly a third $22(31.4 \%)$ of the participants with VI were in the bilateral moderate VI category. Among the overall prevalence of visually impaired adults 27 (6.49\%) had bilateral VI and 43 (10.34\%) had monocular VI (See Table 4).

Refractive error was the most common cause of bilateral VI and cataract caused most of the unilateral VI (See Fig. 1).

\section{Factors associated with visual impairment in adults}

In multivariable analysis age, history of eye trauma, family history of eye problem, family size and educational status had statistically significant positive association with VI.

Adults aged 40-60 years were 3 times more likely to present with VI compared to those aged 18-39 years; adults aged > 64 years were even 12 times more likely.

Table 3 Systemic co-morbidity and behavioral characteristics of adults aged $\geq 18$ years at Debre Berhan town, North Shewa, Ethiopia, 2018 ( $n=416, n=$ number of study participants)

\begin{tabular}{llll}
\hline Variables & Category & Frequency & Percentage (\%) \\
\hline Known history of hypertension & Yes & 21 & 5.0 \\
& No & 395 & 95.0 \\
Known history of diabetes & Yes & 9 & 2.2 \\
& No & 407 & 97.8 \\
Cigarette smoking & Yes & 11 & 2.6 \\
& No & 405 & 97.4 \\
History of eye trauma & Yes & 28 & 6.7 \\
History of eye check up & No & 388 & 93.3 \\
& Yes & 133 & 32.0 \\
Eye glass wear & No & 283 & 68.0 \\
& Yes & 101 & 24.3 \\
\hline
\end{tabular}

Those who had family history of eye problems were 7 times more likely to have VI than adults with no history of family eye problems. Adults who had a history of eye trauma were 4 times more likely to have VI than those who had no previous eye trauma history. Illiterate adults were 3 times more likely to have VI than literate adults (See Table 5).

\section{DISCUSION}

Prevalence of visual impairment among adults aged $\geq$ 18 years in this study was $16.8 \%$ (95\% CI: $13.5,20.2 \%$ ) which is higher than other studies done in South Sudan (11.8\%) [10], Cape Town South Africa (7.2\%) [16], Sokoto state of Nigeria (11\%) [17], Atakunmosa, South Western Nigeria (7.4\%) [18], Bangladesh (9.3\%) [19], Malaysia (9.2\%) [20], South Korea (4.3\%) [21], East Delhi district of India (11.4\%) [6], Mahabubanagar district of India (8.4\%) [22], Iran (1.39\%) [23] and Botucato, Brazil (7.4\%) [24].

The studies in South Sudan, Sokoto and Atakunmosa, Nigerian state, Brazil, Bangladesh, Mahabubanagar district of Indian and Malaysian were done by better eye presenting visual acuity which means they considered bilateral VI only. If one eye was visually impaired and the other was not impaired, they considered as no VI which under estimate the magnitude of VI compared to the present study which considered the visual acuity of either eye. The lower prevalence of VI in Cape Town South Africa might be caused by differences in socioeconomic variables and access of eye care services. The Iran and Korean studies were based on best corrected better eye visual acuity which might under estimate the burden of VI.

The prevalence of visual impairment in this study is lower than the studies reported by Upper Egypt (38.8\%) [9], Cocoa farmers of Ghana (22.7\%) [8], Saudi (23.5\%) [5] and rural areas of Coastal Karantaka, India (25.7\%) [7]. 
Table 4 Frequencies of $\mathrm{VI}$ categories among adults aged $\geq 18$ years with visual impairment at Debre Berhan town, North Shewa, Ethiopia, 2018 ( $n=70, n=$ number of adults with visual impairment)

\begin{tabular}{|c|c|c|c|}
\hline Visual impairment category & & Frequency & Percentage (\%) \\
\hline$<6 / 18-6 / 60$ & Bilateral moderate VI & 22 & 31.4 \\
\hline$<6 / 60-3 / 60$ & Bilateral sever VI & 2 & 2.9 \\
\hline$<3 / 60-N L P$ & Bilateral blindness & 3 & 4.3 \\
\hline$<6 / 18-6 / 60$, other eye $6 / 6-6 / 18$ & Monocular moderate $\mathrm{Vl}$ & 21 & 30.0 \\
\hline$<6 / 60-3 / 60$, other eye $6 / 6-6 / 60$ & Monocular sever VI & 4 & 5.7 \\
\hline$<3 / 60-N L P$, other eye $6 / 6-3 / 60$ & Monocular blindness & 18 & 25.7 \\
\hline Total & & 70 & 100.0 \\
\hline
\end{tabular}

The possible discrepancy between the studies in Upper Egypt and cocoa farmers of Ghana compared to this study might be due to study area and population difference in which they studied on rural and aged $\geq 40$ years populations. The study in Saudi had used $6 / 9$ as a lowest cut of point of visual acuity to define VI [5] unlike in the current study that used the lowest cut of point of visual acuity for VI was $6 / 18$ [1] which may be the possible reason for the discrepancies.

The prevalence of visual impairment in this study is in line with the studies done in China (17.17\%) [25], Andhra Pradesh state of India (14.3\%) [4] and Southern Mexico (14.1\%) [26]. This may be due to studying the same ages of the populations ( $\geq 18$ years), use of presenting visual acuity and similar cut of point $(\mathrm{VA}<6 / 18)$ for defining VI.

In this study, illiteracy is positively associates with visual impairment which was similar that found by other studies done in China [25], rural area of Karntaka India [27], Cape Town, South Africa [16], Southern Mexico [26]. The possible reason for this trend of VI may be poor health related behaviors in illiterates [28].
Age $\geq 40-64$ years are positively associated with VI which was supported by studies done in Singapore [29], South Africa [16], China [25], South Korea [21] Western Cameroon [30], Southern Mexico [26], and Nigeria [18] that may be related to an increased prevalence of age related eye diseases and degenerations in these age groups [31].

History of trauma to the eye had 4 times more likely to have VI which can be explained due to deterioration of the eye structure, functional loss and exposure to ocular infections following trauma.

Visual impairment in adults with family history of eye problems is nearly 7 times higher than no family history which may be due to inheritance of genetic factors.

In adults within $>5$ family size is nearly 4 times more likely to have VI compared to those adults within $<2$ family size which can be explained due to difficulty to cater for the provision of food, health service use, education and low standard of leaving for the siblings in such large families [32].

Since community based study on the presenting visual acuity was not conducted in the study area or other similar areas which had related population

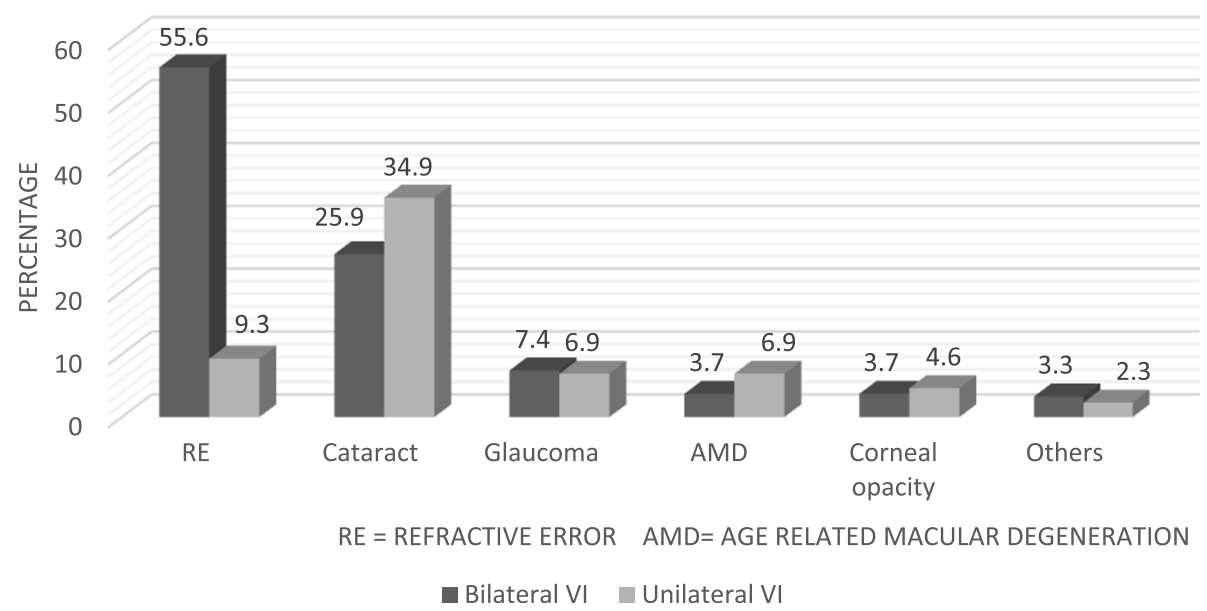

Fig. 1 Common ocular abnormalities that caused bilateral and unilateral visual impairment among visually impaired adults aged $\geq$ years at Debre Berhan town, North Shewa, Ethiopia, 2018. Refractive error and cataract were the leading cause of bilateral and unilateral VI respectively 
Table 5 Factors associated with visual impairment among adults aged $\geq 18$ years at Debre Berhan town, Ethiopia, 2018 ( $n=416$, $n=$ number of study participants)

\begin{tabular}{|c|c|c|c|c|c|}
\hline \multirow[t]{2}{*}{ Factors } & \multicolumn{2}{|c|}{ Visual Impairment } & \multirow[t]{2}{*}{$\operatorname{COR}(95 \% \mathrm{Cl})$} & \multirow[t]{2}{*}{$\mathrm{AOR}(95 \% \mathrm{Cl})$} & \multirow[t]{2}{*}{$p$-value } \\
\hline & No & Yes & & & \\
\hline \multicolumn{5}{|l|}{ Age (year) } & 0.0001 \\
\hline $18-39$ & 222 & 13 & 1.0 & 1.0 & \\
\hline $40-64$ & 100 & 23 & $3.93(1.91-2.8 .07)$ & $3.04(1.22-7.58)$ & 0.017 \\
\hline$>64$ & 24 & 34 & $24.19(11.25-52.01)$ & $12.18(4.47-33.20)$ & 0.0001 \\
\hline \multicolumn{5}{|l|}{ Marital status } & 0.058 \\
\hline Single & 141 & 37 & $1.63(0.97-2.73)$ & $2.06(0.98-4.37)$ & \\
\hline Married & 205 & 33 & 1.0 & 1.0 & \\
\hline \multicolumn{5}{|l|}{ Education level } & 0.007 \\
\hline Illiterate & 26 & 29 & $8.71(4.68-16.20)$ & $3.02(1.36-6.72)$ & \\
\hline Literate & 320 & 41 & 1.0 & 1.0 & \\
\hline \multicolumn{5}{|l|}{ Family income } & 0.491 \\
\hline (US\$) & 74 & 32 & $3.85(1.78-8.35)$ & $2.20(0.78-6.20)$ & 0.137 \\
\hline$<57.31$ & 108 & 19 & $1.57(0.69-3.54)$ & $1.40(0.52-3.76)$ & 0.506 \\
\hline $57.31-101.07$ & 75 & 9 & $1.07(0.41-2.77)$ & $1.67(0.54-5.17)$ & 0.373 \\
\hline $101.11-51.61$ & 89 & 10 & 1.0 & 1.0 & \\
\hline \multicolumn{6}{|l|}{$>151.61$} \\
\hline \multicolumn{5}{|l|}{ Hypertension } & 0.840 \\
\hline Yes & 15 & 6 & $2.07(0.77-5.53)$ & $1.14(0.33-3.87)$ & \\
\hline No & 331 & 64 & 1.0 & 1.0 & \\
\hline \multicolumn{5}{|l|}{ Diabetes } & 0.278 \\
\hline Yes & 5 & 4 & $4.13(1.08-15.80)$ & $2.47(0.48-12.63)$ & \\
\hline No & 341 & 66 & 1.0 & 1.0 & \\
\hline \multicolumn{5}{|c|}{ Family history of eye problem } & 0.003 \\
\hline Yes & 9 & 7 & $4.16(1.50-11.58)$ & $7.02(1.95-25.22)$ & \\
\hline No & 337 & 63 & 1.0 & 1.0 & \\
\hline \multicolumn{5}{|l|}{ History of trauma } & 0.003 \\
\hline Yes & 18 & 10 & $3.61(1.61-8.09)$ & $4.44(1.64-12.04)$ & \\
\hline No & 328 & 60 & 1.0 & 1.0 & \\
\hline \multicolumn{5}{|l|}{ Occupation } & 0.595 \\
\hline Employed & 141 & 14 & 1.0 & 1.0 & \\
\hline Unemployed & 205 & 56 & $2.75(1.48-5.13)$ & $1.24(0.56-2.72)$ & \\
\hline \multicolumn{5}{|l|}{ Cigarette smoke } & 0.287 \\
\hline Yes & 7 & 4 & $2.93(0.83-10.31)$ & $2.42(0.42-12.29)$ & \\
\hline No & 339 & 66 & 1.0 & & \\
\hline \multicolumn{5}{|l|}{ Family size } & 0.077 \\
\hline$<2$ & 104 & 12 & 1.0 & 1.0 & \\
\hline $2-4$ & 159 & 30 & 1.64(0.80-3.34) & $2.25(0.83-6.14)$ & 0.113 \\
\hline $4-5$ & 39 & 9 & $2.00(0.78-5.12)$ & $2.25(0.63-8.03)$ & 0.210 \\
\hline$>5$ & 44 & 19 & $3.74(1.68-8.36)$ & $4.44(1.43-13.75)$ & 0.010 \\
\hline
\end{tabular}

characteristics and methodology of the current study, $50 \%$ proportion of sample size determination might overestimated the prevalence. In addition this study might have an inheritance limitations of the crosssectional study design and information bias due to the tools that used to collect ocular trauma history and 
family ocular history. Because of the study used broad cigarette smoking categories from references different from the study area, the result might have a limitation to signify the variable in the study area.

\section{Conclusion}

Prevalence of visual impairment was significant public health problem among adults at Debre Berhan town. Advanced age, history of eye trauma, illiteracy, large family size and family history of eye problems were positively associates with visual impairment.

\begin{abstract}
Abbreviations
AOR: Adjusted Odds Ratio; Cl: Confidence Interval; COR: Crude Odds Ratio; EPI INFO: Epidemiological Information; NLP: No Light Perception; PVA: Presenting Visual Acuity; SPSS: Statistical Package for Social Science; VA: Visual Acuity; VI: Visual Impairment; WHO: World Health Organization
\end{abstract}

\section{Acknowledgements}

We are deeply indebted University of Gondar for gave ethical clearance to conduct this research. We would also like to acknowledge study participants for their cooperation and willingness in the whole data collection offer.

\section{Authors' contributions}

NL: Wrote proposal, conducted data collection and analysis, wrote thesis and prepared manuscript, AW: Revised proposal \& thesis, conducted data collection and analysis, NF: Reviewed the literature, revised proposal, thesis manuscript and participated in data collection. All authors have read and approved the final version of the manuscript.

\section{Funding}

The authors received no any financial support for the research, authorship, and/or publication of this article.

\section{Availability of data and materials}

All the data supporting the findings are contained within the manuscript. If any additional information is required, all the necessary data will be available with the principal investigator (Natnael Lakachew Assefa with email: natiuog@gmail.com)

\section{Ethics approval and consent to participate}

Ethical clearance was obtained from University of Gondar College of Medicine and Health Science School of Medicine ethical review committee and written letter of permission was obtained from Debre Berhan town woreda health office. Written informed consent was obtained from each study participants after explaining the purpose of the study. They had full right to participate and to refuse or with draw at any time they want from the study.

\section{Consent for publication}

Not applicable

\section{Competing interests}

All the authors declared no any potential conflicts of interest with respect to the research, authorship, and/or publication of this article.

\section{Author details}

${ }^{1}$ Department of Optometry, School of Medicine, College of Medicine and Health Science, University of Gondar, Gondar, Ethiopia. ${ }^{2}$ Debre Berhan Referral Hospital, North Shewa, Ethiopia.

Received: 29 August 2019 Accepted: 28 July 2020

Published online: 03 August 2020

\section{References}

1. WHO. ICD update and revision platform: change the definition of blindness, vol. 8; 2010. availabele@http://www.who.int//blindness/Change\%20the\% Definition\%of\%Blindness. Accessed on 14/3/2018.
2. Dandona L, Dandona R. Revision of visual impairment definitions in the international statistical classification of diseases. BMC Med. 2006;4(1):7.

3. Flaxman SR, Bourne RR, Resnikoff $S$, Ackland P, Braithwaite T, Cicinelli MV, et al. Global causes of blindness and distance vision impairment 1990-2020: a systematic review and meta-analysis. Lancet Glob Health. 2017;5(12): e1221-e34.

4. Marmamula S, Narsaiah S, Shekhar K, Khanna RC, Rao GN. Visual impairment in the south Indian state of Andhra Pradesh: Andhra Pradesh - rapid assessment of visual impairment (AP-RAVI) project. PLoS One. 2013;8(7): e70120.

5. Parrey MRAF. Prevalence and causes of visual impairment among Saudi adults. Pak J Med Sci. 2017;33(1):167-71.

6. Gupta N, Vashist P, Malhotra S, Senjam SS, Misra V, Bhardwaj A. Rapid assessment of visual impairment in urban population of Delhi, India. PLoS One. 2015;10(4):e0124206.

7. Court H, McLean G, Guthrie B, Mercer SW, Smith DJ. Visual impairment is associated with physical and mental comorbidities in older adults: a crosssectional study. BMC Med. 2014;12(1):181.

8. Boadi-Kusi SB, Hansraj R, Mashige KP, Osafo-Kwaako A, llechie AA, Abokyi S. Prevalence and causes of visual impairment and blindness among cocoa farmers in Ghana. Ophthalmic Epidemiol. 2017;24(1):17-23.

9. Mousa A, Courtright P, Kazanjian A, Bassett K. Prevalence of low vision and blindness in upper Egypt. Ophthalmic Epidemiol. 2014;21(3):190-6.

10. Ngondi J, Ole-Sempele F, Onsarigo A, Matende I, Baba S, Reacher M, et al. Prevalence and causes of blindness and low vision in southern Sudan. PLoS Med. 2006;3(12):e477.

11. Berhane Y, Worku A, Bejiga A, Adamu L, Alemayehu W, Bedri A, et al. Prevalence of blindness and low vision at the national and regional levels in Ethiopia. Ethiop J Health Dev. 2007:21(3):204-10.

12. Bourne RRA, Flaxman SR, Braithwaite T, Cicinelli MV, Das A, Jonas JB, et al. Vision loss expert group. Magnitude, temporal trends, and projections of the global prevalence of blindness and distance and near vision impairment: a systematic review and meta-analysis. Lancet Glob Health. 2017:5(9):e888-97.

13. WHO. 10 Facts about Blindness and Visual Impairment. 2014: Available online: http://www.who.int/features/factfiles/blindness/en. Accessed on $\operatorname{march} / 2018$.

14. Harrabi HAM-J, Zunzunegui MV, Haddad S, Freeman EE. Visual Difficulty and Employment Status in the World. PloS one. 2014;9(2).

15. Bilano V, Gilmour S, Moffiet T, d'Espaignet ET, Stevens GA, Commar A, et al. Global trends and projections for tobacco use, 1990-2025: an analysis of smoking indicators from the WHO Comprehensive information Systems for Tobacco Control. Lancet. 2015;385(9972):966-76.

16. Cockburn NSD, Lecuona K, Joubert F, Rogers G, et al. Prevalence, causes and socio-economic determinants of vision loss in Cape Town, South Africa. PLoS ONE. 2012;7(2):e30718.

17. Muhammad N, Mansur RM, Dantani AM, Elhassan E, Isiyaku S. Prevalence and causes of blindness and visual impairment in Sokoto state, Nigeria: baseline data for vision 2020: the right to sight eye care programme. Middle East Afr J Ophthalmol. 2011;18(2):123-8.

18. Onakpoya OH, Adeoye AO, Akinsola FB, Adegbehingbe BO. Prevalence of blindness and visual impairment in Atakunmosa west local government area of southwestern Nigeria. Tanzan Health Res Bull. 2007:9(2):126-31.

19. Dineen BP, Bourne RR, Ali SM, Huq DM, Johnson GJ. Prevalence and causes of blindness and visual impairment in Bangladeshi adults: results of the National Blindness and low vision survey of Bangladesh. Br J Ophthalmol. 2003:87(7):820-8.

20. Rozhan SMRHI, Shah SA. Visual impairment and its associated factors among the adult population of Kuala pajam village, Branang, Selangor, Malaysia. J Commun Health. 2009;15:2.

21. Tyler H, Rim MC, Lee SC, Lee CS. Prevalence and risk factors of visual impairment and blindness in Korea: the Fourth Korea National Health and Nutrition Examination Survey in 2008-2010. Acta Ophthalmol. 2014;92(4): $317-25$

22. Mactaggart I, Polack S, Murthy G, Kuper H. A population-based survey of visual impairment and its correlates in Mahabubnagar district, Telangana state, India. Ophthalmic Epidemiol. 2018;25(3):238-45.

23. Fotouhi A, Hashemi H, Mohammad K, Jalali K. The prevalence and causes of visual impairment in Tehran: the Tehran Eye Study. Br J Ophthalmol. 2004; $88: 740-5$. 
24. Schellini SA, Durkin SR, Hoyama E, Hirai F, Cordeiro R, Casson RJ, et al. Prevalence and causes of visual impairment in a Brazilian population: the Botucatu eye study. BMC Ophthalmol. 2009;9(1):8.

25. Guo C, Wang Z, He P, Chen G, Zheng X. Prevalence, causes and social factors of visual impairment among Chinese adults: based on a National Survey. Int J Environ Res Public Health. 2017;14(9):1034.

26. Aida Jimenez-Corona MEJ-C, Samuel Ponce-de-Leon,. Social Determinants and Their Impact on Visual Impairment in Southern Mexico. Ophthalmic Epidemiol 2015;22 (5): 342-348.

27. Rao CR, Shetty RS, Narayanan SS, Kini S, Kamath V, Kamath A. Prevalence of visual impairment in adults aged 18 years and above in a rural area of coastal Karnataka. Int J Health Allied Sci. 2018;7(1):31.

28. Berkman ND, DeWalt DA, Pignone MP, Sheridan SL, Lohr KN, Lux L, et al. Literacy and health outcomes. Evid Rep Technol assess. 2004;87(04):E007-2.

29. Wah W, Earnest A, Sabanayagam C, Cheng C-Y, Ong MEH, Wong TY, et al. Composite measures of individual and area-level socio-economic status are associated with visual impairment in Singapore. PLoS One. 2015;10(11): e0142302.

30. Oye J, Mactaggart I, Polack S, Schmidt E, Tamo V, Okwen M, et al. Prevalence and causes of visual impairment in Fundong District, North West Cameroon: Results of a Population-Based Survey. Ophthalmic Epidemiol. 2017:24(6):394-400.

31. Group A-REDSR. The age-related eye disease study (AREDS): design implications AREDS report no. 1. Control Clin Trials. 1999;20(6):573.

32. Bronson P, Merryman A. NurtureShock: new thinking about children: Hachette UK; 2009 .

\section{Publisher's Note}

Springer Nature remains neutral with regard to jurisdictional claims in published maps and institutional affiliations.

Ready to submit your research? Choose BMC and benefit from:

- fast, convenient online submission

- thorough peer review by experienced researchers in your field

- rapid publication on acceptance

- support for research data, including large and complex data types

- gold Open Access which fosters wider collaboration and increased citations

- maximum visibility for your research: over $100 \mathrm{M}$ website views per year

At $\mathrm{BMC}$, research is always in progress.

Learn more biomedcentral.com/submissions 